\title{
Research on Brand Marketing Management from the Perspective of Customers
}

\author{
Ge Hongying \\ Institute of Economic Management Jilin Institute of Agricultural Science and Technology, Jilin 132101, \\ China \\ gehongying@126.com
}

Keywords: Customer marketing management, brand management, brand relationship

\begin{abstract}
In twenty-first Century, the development of information technology and Internet, the market of power back from the enterprise to the customer, the customer has the right to choose and the right to speak of the changing nature of the market hitherto unknown, caused by traditional 4Ps marketing mix to trade as the core, characteristics of marketing management theory has been replaced by a new type of $4 \mathrm{Cs}$ is to maintain customer relationship orientation, and obtain customer lifetime value as the center of the concept of "relationship marketing" theory. Under this condition, the traditional brand management has become increasingly pale, brand relationship management came into being. This paper mainly expounds the brand relationship from the perspective of customers. With the development of information technology and Internet, the market right has been transferred from the enterprise to the customer. The customer has the option and the right to speak. In a large number of homogeneous products on the market, enterprises only rely on low price "fight", cannot retain customers. It is difficult for the products and services that lack the brand relationship advantage to survive and develop. Only by recognizing the true meaning of relationship management between customers and brands, can we effectively sell good products and enhance the market competitive advantage of enterprise brands.
\end{abstract}

\section{Introduction}

Due to the rapid changes in the competitive environment, the shortening of product life cycle, industry structure adjustment, the continuous influx of competitors and substitutes, the market is gradually shrinking, a large number of marketing costs increased sharply, enterprises are facing more and more pressure or deviate from the loss of customers. In the traditional brand management is feeble under the condition of being brand relationship management, it is the brand management method to the customer relations as the center, its essence is the transformation from the transaction to the relationship, with the most valuable customers carefully, and only the most valuable customers to establish a good relationship, marketing resources the enterprises will be scarce. To the most effective configuration and utilization. One of the main sources to enhance the competitiveness of enterprises, the operation of the industry has brought prosperity to the research of brand theory. So far, the Western brand theory research has entered the brand relationship research stage after experiencing the brand stage, brand strategy stage, brand asset stage and brand management stage. From this stage, the relationship between brand and customer has gradually become the focus of brand theory research. As a new stage of brand theory research, brand relationship has opened up a new academic field at least in four aspects:First,the arrival of experience economy. Joseph of the United States. Pine II and James Gilmore in the United States? "Harvard Business Review" magazine in 1998 7-8 month, "welcome to the experience economy" (Welcome tothe Experience Economy) pointed out: experience economy era has come, people's needs and desires, customer consumption patterns also affected. Experience is essentially a customer's memorable experience, and a strong brand is to give the customer this feeling, this feeling will deepen and enrich the relationship between brands and customers. To grasp the brand of customer experience, we must grasp the customer experience economy era of consumer behavior, mainly displays in: one is the content of consumption, demand for personalized products and 
services is more and more high.

People are increasingly seeking products or services that can shape their own personal image and highlight their own uniqueness. Two, in the consumption structure, the proportion of emotional demand increases. Customers pay more attention to the pleasure and satisfaction of emotion while paying attention to the quality of products. People pay more attention to the closeness of the relationship between the product and themselves, and the emotion that resonates with the psychological needs of the self. Commodity. Three is in the value goal, the customer from pays attention to the product itself to pay attention to accept the product the feeling. The most typical is the success of Starbucks coffee in the coffee market. In addition, customer participation and interactive services are becoming more and more popular. In the way of accepting products, people are no longer satisfied with passively accepting the inducement and manipulation of enterprises, but actively participating in the production. Design and manufacture of products in order to achieve greater sense of accomplishment and satisfaction.Secondly, the prevalence of relationship marketing. The concept of relationship marketing is an epoch-making idea. Since then, the focus of marketing has shifted from transaction to relationship (Webster, 1992; Pepper\&Rogers, 1993). Today, the types and quantities of products and brands are increasing rapidly, and the sources of information and pipelines are expanding rapidly, especially the wide application of the Internet. Consumers have a large amount of information, resulting in two-way communication. The starting point is the customer relationship marketing concept, the enterprise as their customers, with the customer's experience to design the product or service, the enterprise and customer win-win situation, to establish a long-term, trust and mutual relations between enterprise and customers, to win customer loyalty, in order to get the enterprise long-term stable development.

\section{The Status of Brand Relationship Management from the Perspective of Customers}

The concept of brand relationship was first proposed by Research International (RI) marketing research firm Max Blackston. He believes that brand relationship is the attitude of consumers to brands. The interaction between brand and consumer attitude." So far, the relevant empirical research on the brand level is particularly scarce. Especially in our country, the theoretical research in this field is still blank. This is closely related to the backward marketing thinking of the majority of enterprises in china. Along with our country market gradually entered the era of relationship marketing, enterprises attach importance to the establishment and maintenance of customer relationship and brand, and the first to the frontier of western theory of brand relationship in-depth understanding and thinking. Details are as follows:Conceptual model of brand relationship. Brand relationship conceptual model describes the research thinking and analysis framework of brand relationship. The academic circles generally believe that the concept of brand relationship was formally proposed by Research International (RI) market research firm Max Black-ston. In 1992, Blackston standardized the definition of brand relationship according to the principle of interpersonal communication, and thought that brand relationship was the interaction between customer's attitude towards brand and brand's attitude toward customers". In this relational system, customers and brands are regarded as two equally important parts and interact with each other. Brand relationship as the enterprise obtain sustainable competitive advantage of the new marketing mode, in order to "relationship", "value" and "competitiveness" as the keyword marketing era, it will be a new mission: to enhance the value and strengthen the competition.Brand relationship role model. Role definition is the basis of brand relationship research, and the emergence of different brand relationships is often due to the difference of brand roles. The significance of brand relationship role research is here. In mid 1990s, Ogilvy \& Mather (O\&M) of the new forces in Asia

- "Sprite generation" conducted a large-scale survey, found that can play five important roles: quality, status, reward, self expression and feeling in the relationship between brand and customers. Among them, the quality of products and the function, status and meet customers "need to face and social sense of respect", the demands of the reward is relaxed, leisurely life style, self express brand on customer self recognition and transfer, the feeling of giving customers imagination. FiveBrand 
roles satisfy five different value requirements of customers.

\section{The Problems of Brand Relationship Management from the Perspective of Customers}

The status quo of brand relationship in china. In Chinese culture, the most powerful determinant of social behavior does not lie in the individual itself, but in the relational context outside the individual. The overwhelming influence of interpersonal relationship reflects the mode of social behavior in Confucian culture, which is compared with Western individualism. This is reflected in the issue of consumer brand relations. Chinese consumers regard branding as a tool to build social relationships. Therefore, the fundamental significance of brand to Chinese consumers lies in the way that reflects the interaction between people and the way they treat society. In a very wide range, some enterprises equate the creation of famous brand with advertising, and think that advertising can create fame and reputation. With the popularity of famous brands, enterprises with overnight fame are very common. In recent years intensified advertising war, some enterprises in order to create sensational effect, blind pursuit of new, strange, special, designed a lot of vulgar and funny junk advertising. These advertising naive disease is in fact the brand consciousness is not clear or eager for quick performance, the result is to advertising instead of brand, only pay attention to product.

Modern enterprise consciousness, the company whether product design or service arrangement, its starting point is the enterprise self as the core, the enterprise staff generally not aware of their work with the consumer relationship. Two, in terms of methods, Chinese enterprises do not have a set of standardized methods, conduct systematic market research, and make a regular and rigorous analysis of consumer consumption trends and consumer behavior. The enterprise did not learn how to grasp the development trend from the perspective of consumer demand to control and guide consumers, so that they long for enterprise products to maintain loyalty and trust; even make better brand enterprise, its marketing management also exists lax management, deep enough, the market reflects the problem of slow. Companies are lack of competitiveness. Three is the most famous brand in the marketing strategy, enterprises have not done a departure from the consumer demand, to actively carry out market segmentation, the continuous development of the special needs of consumers, and actively control the final consumer, through to these segments of the interest groups, launched various varieties and structure of products, effectively blocked in the market competition the gap, the successor to the development of effective control There is no way in., competitors. In the brand development process, confusion and blindness has become one of the most significant problems, the role of dislocation, lack of intrinsic motivation so that people have deeper, namely from the system thinking of restricting China's brand development obstacles. The mechanism is not active, unreasonable structure, debt and social burdens, backward technology and equipment, poor management, low economic benefits seriously restricts the formation and development of our brand, these problems and difficulties, many are under the existing institutional arrangements to solve, therefore, must take system innovation and brand development together. China's market development degree is low, all kinds of market development is not balanced, especially the elements of the market development lag, weak market price mechanism, straighten out the various price is still more difficult; the competition mechanism is equal, market behavior is not standardized; a unified national market has not been set up, regional blockade, market segmentation has not been resolved; the market parameters is chaotic, the market signals are not real; from each other all kinds of market, lack of penetration, with the. The low degree of market development has fundamentally led to the disorder of competition and the difficulty of rational allocation of resources. The soft constraints of market competition rules lead to unfair competition spread, trading rules, the arbitration rules are not unified, not perfect, so that a large number of fake brand-name enterprises were able to escape the disaster; weak market entry and exit rules, make the brand not free enterprise has the ability to enter and exit inferior enterprises and there are serious rigid restriction. 


\section{Our Coping Strategies}

Perfect brand relationship strategy. From the brand life cycle law, advertising to promote the brand to import only a means of lofty transition from ordinary, truly embodies the brand of high quality and high reputation and high market share and high economic benefits. The scientific and technological level, design level, technological level, management level and marketing level of the enterprise are all materialized in the famous brand. Therefore, creating famous brand is the competition of the comprehensive strength of the enterprise in the final analysis. The advertisement can only publicize the "internal strength" and "essence" of the famous brand". From the brand promotion planning strategy, brand promotion planning success should include two aspects of advertising and publicity, the ultimate purpose of all advertising is to let people know the brand, but all the role of propaganda is to let people know the connotation of the brand value. When the brand is introduced into the early stage, it can be praised through TV, newspapers, outdoor, gifts and other forms of advertising. When the brand has taken shape in a certain range, it needs to be promoted by means of news report, public welfare activity, appraisal and identification, Zhang Qishi. Let the visibility and reputation of complement each other, the different phases of the proportion with the brand promotion form effective combination, the only way to establish a good reputation based on reputation, won great fame from a good reputation, and ultimately the formation of brand cognitive Haku Chusei. The life of a product is periodic, and the brand is older and more valuable. Chinese enterprises must consider the relationship between products and brands in the early stage of brand creation. They can learn from the methods of "total trademark (brand), series of products (or products)" adopted by international famous brands. Idea is the soul of brand and the embodiment of enterprise's strength, benefit and management essence. The production is not only the product, the more important is the quality and reputation is more important than money is the idea, idea is the premise of management decision, the enterprise must use explicit beliefs, ideals, purposes and business philosophy, with lofty goals and values to persuade people, unite people, inspire people, to the greatest limitexcavates, release, guide and improve the employee's potential, let the brand can not shine in any case.

\section{Conclusion}

Strategic brand marketing has a very important and long-term significance for the current Chinese market. China enterprises after more than 20 years of construction, there have been a lot of advanced ideas, good foundation, strength, vision of large enterprises, these enterprises and multinational companies in comparison although it looks quite naive, but we also see the maturity values brought by the stable operating performance. At the same time, we also feel that the strategic short board in the process of China's enterprise development is also very obvious. Because I have long been employed in the fast moving consumer goods industry in China, the feeling of the enterprise is even more profound. First of all, the strategy of brand marketing will fundamentally change in the concept of Chinese enterprise makes the enterprises have China care for this and lose that phenomenon, strategic thinking ability and professional judgment skills in a more comprehensive development. Chinese now is not the lack of bias type enterprise, China is the lack of versatile enterprises, as long as the solution to the general business confusion, Chinese enterprises have entered the global competition may. Secondly, the strategy of brand marketing in the tool design show very professional wisdom, through the deep understanding of Western marketing theory, the construction of user-friendly, strong operability of professional tools system, reduce China enterprises and explore the law of time. Third, strategic brand marketing will use Chinese cases and Chinese market facts, through the profound insight into the Chinese market, to solve the strategic brand marketing system in China market. We have seen many from famous consulting companies, brand marketing thinking, famous foreign enterprises but because western countries earlier established a market economy system, the standardization of the market is more and more high, the brand marketing theory in the west is often impossible to solve practical 
problems, facing the Chinese market so the book is hope through the local enterprise culture strategy brand marketing theory. Fourth, the strategy of brand marketing strategy, for the first time in the brand, marketing, brand strategy, marketing strategy, establish a comprehensive and profound link of brand marketing and brand marketing strategy, build a comprehensive strategic thinking model based on the local market Chinese enterprises. Fifth, strategic brand marketing is also engaged in brand strategy, advertising, marketing management consulting, to provide a new thinking of enterprise senior marketing personnel and academic circles, based on the strategy, brand marketing, popular exposition and construction tools to build a new platform system.

\section{Acknowledgement}

Under the background of "Internet + " raw honey b2c marketing model innovation research 201611439020.

\section{References}

[1] W.Y. How to enhance the core value of Chinese national brand. Business research, 2013.

[2] Y. X ,S.Q. P. The influencing factors of consumer brand relationship: an exploration Sex studies. Business research, 2012.

[3] Y.F.C , Y.P.Q. Customer retention and its influencing factors from the perspective of relationship marketing Element analysis, 2010

[4] Ma Yingshuang, Zhang Haomin: "analysis" the relationship between customer satisfaction and customer loyalty. Enterprises, 2010

[5] L.L. Research on the promotion strategy of customer value from the perspective of brand relationship

Industry, technology and economy, 2009The background and research background of brand relationship management under the customer perspective from [6], Shanxi, Shanxi and so on Status quo, 2008

[7] A.Z.H, Y.L. On consumer brand trust in the life cycle of brand relationship. The establishment of psychological contract. Business research, 2012 